\title{
Land Suitability and Crop Pattern Model using Integrated Pollination Intelligence Algorithm and Remote Sensing
}

\author{
A. E. Akinsunmade ${ }^{1,{ }^{*}}$ and C. N. Ejieji ${ }^{2}$ \\ ${ }^{1}$ Department of Mathematics, Faculty of Physical Sciences, University of Ilorin, Ilorin, Nigeria \\ e-mail: akintayoakinsunmade@gmail.com \\ ${ }^{2}$ Department of Mathematics, Faculty of Physical Sciences, University of Ilorin, Ilorin, Nigeria \\ e-mail: ejieji.cn@unilorin.edu.ng
}

\begin{abstract}
A mathematical model for crop pattern coupled with economic and environmental factors of agricultural production constructed with remote sensing and metaheuristic based algorithm is considered in this work. The model is expected to serve as a support system for farm managers' decision making process. Geographic data showing soil properties of major cities in Benue State, Nigeria using remote sensing, was integrated to the model to obtain analyzed suitability information for selected crops. A class of modern optimization algorithms was thereafter used to find optimum cropland pattern. A net production value of $\$ 1,592,107,000.00$ was obtained by using the model compared to an initial production value of $\$ 1,364,460,000.00$ recorded in the study area. The study suggests that soil properties must be considered along side with economic factors before choosing the types of crop to be planted on a piece of land. This study has shown the efficacy of optimization tools which should be dully employed by farmers in decision making process. The data used to support the findings of this study are included within the article.
\end{abstract}

Received: June 18, 2020; Accepted: June 29, 2020

2010 Mathematics Subject Classification: 91B76, 90C59, 90C90.

Keywords and phrases: mathematical model, geographic information system, agricultural production, metaheuristic optimization methods. 


\section{Introduction}

Management of agricultural systems has gone beyond the use of intuition process, although intuition process cannot be completely swept off in agricultural management, as there are known traditional methods culled from intuition making process which turned to be useful tips in agricultural practices. However, the world is changing with technological advancements that proved to be useful in all facets of life. There are many technicalities in agricultural systems and management processes and the use of intuition may not be accurate enough if farm managers are to put into consideration sensitive information that will aid good production output. With daily increase in population, there is urgent need to develop new agricultural management patterns to catch up with increasing food demands which is a major problem faced by the agricultural sector. Farm managers must be equipped with useful information that will guide their decision making process. Although agricultural extension services have tried in equipping farmers with basic information, there are increasing needs for updates as technological systems advance on a daily basis. The problem faced by the agricultural sector is not mainly non availability of farmers and investors, it also includes inability to properly manage few available resources so as to meet set targets. For instance, a farmer who plants a crop by having prior knowledge of how suitable the land is in planting his crop of interest has high chances of meeting his set production target, compared to another with little or no knowledge. Thus, to meet production targets, factors like low yield of crops which is subject to weather conditions, pest/diseases, soil fertility, viability of seed must be considered in farm management system. Another important factor that must be considered is land, as crop allocated with small cultivation space can turn out to have high yield amidst other selected crops planted by a farmer or group of farmers, Aimin [1].

Optimization and operation research which are important branches of mathematics can be employed to address problems of this form, by looking into a best possible means in which farmers' land resources can be distributed under certain conditions such that the desired production goal is achieved. Development of optimization algorithms and mathematical schemes for this problem will go 
a long way to aid agricultural decision making process. The most trending method for the solution of optimization problems are called modern methods and these include Genetic Algorithm (GA) Holand [2], Simulated Annealing (SA) Kirkpatrick et al. [3], Differential Evolution Method (DE) Storm and Price [4], Firefly Algorithm (FA) Yang [5], Flower Pollinated Algorithm Yang [6], to mention but a few.

A number of mathematical methods and models have been developed as support tools in agricultural management and decision making process, while the use of linear programming approach, Raj [7], Cambel et al. [8], Wankhade and Lunge [9] for optimal crop planning is the most employed. Researchers like Ahmed et al. [10] and Majeke et al. [11], did a thorough investigation looking into different factors that affect crop productivity using mathematical and statistical approach. Metaheuristic approach based on algorithm development has also been employed to help farmers' decision making process, Agelo [12], Ashutosh et al. [13], Ejieji and Akinsunmade [14]. Most of these works addressed agriculture management system from economic point of view by considering market price of crops, demand of crops and other farm inputs.

In a realistic approach, productivity might not be guaranteed as recorded in most models that consider economic factors only. Other factors that necessitate crop production like soil fertility, land suitability, climate (rainfall, temperature), soil information and properties such as alkalinity and acidity properties of a farm land have not been considered in farm management models. Land and climate suitability need to be considered for effective agricultural planning. According to FAO [15], suitability is needed as well as economic, social and environmental factors in developing an effective and efficient farm management scheme, because lack of suitability analysis has led to inappropriate cropping patterns and land degradation. Soil properties and land suitability must be taken into consideration before planting crops of interest on a certain piece of land. A qualitative analysis of land suitability evaluation must capture information about soil properties, vegetation, topography, hydrology and climate. Some framework on land suitability classification have been suggested in literature but the land suitability classes framework used by Sys et al. [16], has been the most employed. 
The classification is based on a 5 Likert scale in decreasing order (very high suitability, high suitability, moderate suitability, low suitability and very low suitability).

Remote sensing using geographic information system has helped in mapping out land behaviors which in turn gives vital information on environmental and soil properties of a geographic location. Mosleh et al. [17], reported that this system helps to know and sustain soil nutrients. Their work captured managing water resources in farm decision making process using multi-objective programing approach. Djaenudin et al. [18], also made a remarkable conclusion in measuring land behavior using remote sensing to map out forest covers and deforestation in Indonesia. Where there is unavailability of reliable hydrological information, satellite imaging has high role to play in getting reliable information about a geographical area, Karms et al. [19]. Remote sensing has shown great promise in identifying crop within an agricultural area or irrigation tools and this can help in crop patterns.

In this research work, a crop model with land suitability analysis obtained from Geographic Information System (GIS) with remote sensing is developed and used as a tool to aid farm managers decision making process. The soil data from Abah and Petja [20], was analyzed based on Likert scale to handle land suitability constraints in the model. A new modified class of metaheuristic algorithm, Pollination Intelligence Algorithm (PIA), Ejieji and Akinsunmade [14], was adopted with parameter modification to solve the new developed model.

\section{Model Formulation and Method}

The following parameters are defined to formulate the model : 
Table 1: Definition of parameters for the model.

\begin{tabular}{cl}
\hline Parameters & Description \\
\hline$I$ & Number of Selectable Crops \\
$N B_{i}$ & Net Production Benefit of Selected Crops \\
$P_{i}$ & Price of Crop $i$ \\
$Y_{i}$ & Yield of Crop $i$ \\
$T Y$ & Total Yield of all Selected Crops \\
$D_{i}$ & Market Demand of Selectable Crops \\
$C_{i}$ & Variable Cost of Planting Crop $i$ per hectare \\
$A_{i}$ & Area of Land Assigned to Crop $i$ \\
$L$ & Total Amount of Land Available for Cultivation \\
$F_{L}$ & Fixed Cost of Land Available for Cultivation \\
$C C P_{i}$ & Total Cost of Planting Crop $i$ \\
$\Omega_{i}$ & percentage area of crop $i$ allocated \\
$S Q_{i}$ & Quality of Seed Planted \\
\hline
\end{tabular}

In formulating the model, farm decision is made by allocating the total resources available on the farm over a period of time. The decision making process of the farmer as concerned in the model is to allocate crops to available land for cultivation such that the process follows a pattern that guarantees maximum profit.

$$
\text { Maximize }=\sum_{i=1}^{I}\left(P_{i} Y_{i}-C_{i}\right) A_{i}-F_{L} .
$$

The objective function equation (1) is constructed putting into consideration the market price $P$, yield of crop $Y$ and cost of planting $C$ as a basis for decision making. Some crops cannot grow well on certain land and regions. Farmers who plant these types of crops in their region must put in place certain measures to enhance the growth of the crop, and in cases where these measures are not put in place, the yield of the crop is affected at the time of harvest. Meanwhile, crop yield varies and this is subject to environmental and climatic factor, quality of seed 
planted, soil parameter and soil fertility. This makes crop yield a very sensitive parameter to be considered in crop planning. Just like market price and yield of crops, cost of planting a crop also varies. The model considers total cost incurred in the process of crop production which includes cost of seedlings, clearing of land, making heaps, fertilizer application, irrigation process, application of herbicides and pesticides, labor expenses and all other expenses incurred till the point of sales.

For optimal allocation, certain conditions are put in place serving as constraint that must be satisfied. Total land available for cultivation is fixed and allocation of land to all crops must not exceed the total land available for cultivation. This constraint is imposed as

$$
\sum_{i}^{I} A_{i} \leq L .
$$

For good crop yield, attention must be paid to the nature of seed/seedlings planted. Poor seed quality is one of the factors that affect crop yield hence inability to meet production target. This constraint handles the quality of seed planted on the farm and it is stated as

$$
S Q_{i} A_{i} \geq 0
$$

where $S Q \in[0,1]$ is the percentage quality of crop seedling planted.

Agricultural practices are embarked upon to meet certain food demand in the region at the end of harvest. This constraint is formulated as

$$
\begin{gathered}
S Q_{i} Y_{i} A_{i} \geq D_{i} \\
S Q_{i} P_{i} Y_{i} A_{i} \geq C_{i} A_{i} .
\end{gathered}
$$

The constraint equation (5) is designed to help recover cost incurred during planting in case there are changes in market strategy of crop and production output which in turn can lead to loss. Meanwhile, the desired goal in agricultural practices is to have profit from all farming activities. In order to maximize the expected total profit from all crops planted, the sum of the product of area for planting each crop and the yield per unit area for the crop planted, should be 
greater than the expected total yield from all crops planted. This constraint is formulated as

$$
\sum_{i}^{I} A_{i} Y_{i} \geq T Y .
$$

As part of efforts to enhancing the production of crops, it is most important to match agricultural practice with appropriate spatial information under adequate conditions. Geographic Information System (GIS) and remote sensing can be extensively used to support decisions for sustainable agricultural development. Soil map from GIS can be used based on the Likert scale to form a land suitability constraints for different crops. The constraint is given as

$$
S_{i}^{\min } \leq A_{i} \leq S_{i}^{\max }
$$

where $S_{i}^{\text {min }}$ and $S_{i}^{\text {max }}$ are the minimum and maximum area of land $A$ suitable for planting crop $i$.

$$
\begin{gathered}
N B_{i}=P_{i} Y_{i} \Omega_{i} L-C_{i} \Omega_{i} L \\
C P P_{i}=C_{i} \Omega_{i} L \\
A_{i} \geq 0
\end{gathered}
$$

equation (8) and equation (9) are set to determine production output of each crop planted, while equation t10 treats the non-negativity of acreage assignment.

The model maximizes net production of all crops given as equation (1) subject to constraint equations (2) to 10). A new class of meta-heuristic optimization method is adopted to solve the model. Pollination Intelligence Algorithm (PIA) discussed by [14], is a variant of nature inspired algorithm modeled by studying pollination process in flowering plants. 


\section{Pollination Intelligence Algorithm}

Minimize $f(x), x=\left(x_{1}, x_{2}, \ldots, x_{d}\right)$

Initialize a population of $n$ flowers/pollen gametes with random solutions

Find the best solution $g_{*}$ in the initial population

Perform an iterative process using $p_{n+1}=\theta p_{n}\left(1-p_{n}\right)$, where $p \in(0,1)$ and

$0<\theta \leq 4 \quad n=(0,1,2, \ldots)$ to set values of $p$

Define a stopping criterion

while $(t<$ MaxGeneration $)$

for $i=1: n$ (all $n$ flowers in the population)

if rand $<p$,

Define the value for $r_{1}, r_{2}, r_{3}$ and $r_{4}$

Perform global pollination using

$$
x_{i}^{t+1}=x_{i}^{t}+r_{1} \sin \left(r_{2}\right)\left|r_{3} g_{*}-x_{i}^{t}\right|, \quad r_{4}<0.5
$$

and

$$
x_{i}^{t+1}=x_{i}^{t}+r_{1} \cos \left(r_{2}\right)\left|r_{3} g_{*}-x_{i}^{t}\right|, \quad r_{4} \leq 0.5
$$

else

Draw e from a uniform distribution in $[0,1]$

Do local pollination via $x_{i}^{t+1}=x_{i}^{t}+e\left(x_{j}^{t}-x_{k}^{t}\right)$

\section{end if}

Evaluate new solutions

If new solutions are better, update them in the population

end for

Find the current best solution $g_{*}$

\section{end while}

Output the best solution found

$r_{1}, r_{2}, r_{3}$ and $r_{4}$ in the algorithm are parameters that are fitted to have a promising search region. Parameter $r_{1}$ dictates the next position regions (or movement direction) which could be either in the space between the solution and 
destination or outside it, this set as $r_{1}=\frac{(T-t) a}{T}$, where $t$ is the current iteration, $T$ is the maximum number of iteration and $a$ is a constant. The parameter $r_{2}=a * \pi *$ rand, defines how far the movement should be towards or outwards the destination. The parameter $r_{3}=a *$ rand gives random weights that is being introduced for the purpose of either bringing the solution towards the best or away from the best. If the value of $r_{3}$ is greater than 1 , the current solution will be away from the best solution, whereas if $r_{3}$ has value less than 1 , the best solution will be much nearer to the current solution. Finally, the parameter $r_{4}$ is a random number between $[0,1]$ used to switch between the Cosine and Sine components.

\section{Model Implementation}

To implement the model, qualitative evaluation of farmers' region is carried out by matching the climate condition, vegetation and soil properties of the proposed land for cultivation with respect to crop requirement. In this work, suitability data of three crops grown in Benue State, Nigeria, were used as well as remote sensing adopted from Abah and Petja [20]. Descriptive statistics of annual crop area in the region between the year 1989 and 2011 obtained from Benue State Agricultural Development Authority (BNARDA) Markurdi, was harvested from Terdoo et al. [21]. The mean data of crop area were expressed based on the suitability map obtained for cassava, yam and rice with a total of 1,225,493 hectares of land mapped out for cultivation in Benue State, Nigeria. The data for the three crops were computed using the average production output of crops in Nigeria as reported by (FAO [22]), to obtain an approximate cropping output in the study area. The data collected are presented in Tables 2, 3, 4 and 5 below. 
Table 2: Suitability classes for rice.

\begin{tabular}{lll}
\hline Suitability classes & Area (hectares) & Percentages \% \\
\hline Very low suitability & $15,325.00$ & 1.25 \\
Low suitability & $183,752.00$ & 14.99 \\
Moderate suitability & $557,051.00$ & 45.46 \\
High suitability & $419,365.00$ & 34.22 \\
Very high suitability & $50,000.00$ & 4.08 \\
\hline Total & $1,225,493.00$ & 100.00 \\
\hline
\end{tabular}

Table 3: Suitability classes for cassava.

\begin{tabular}{lll}
\hline Suitability classes & Area (hectares) & Percentages \% \\
\hline Very low suitability & $9,690.00$ & 0.79 \\
Low suitability & $412,749.00$ & 33.68 \\
Moderate suitability & $590,452.00$ & 48.18 \\
High suitability & $209,313.00$ & 17.08 \\
Very high suitability & $3,289.00$ & 0.27 \\
\hline Total & $1,225,493.00$ & 100.00 \\
\hline
\end{tabular}

Table 4: Suitability classes for yam.

\begin{tabular}{lll}
\hline Suitability classes & Area (hectares) & Percentages $\%$ \\
\hline Very low suitability & $59,854.00$ & 4.88 \\
Low suitability & $362,386.00$ & 29.57 \\
Moderate suitability & $598,641.00$ & 48.85 \\
High suitability & $199,480.00$ & 16.28 \\
Very high suitability & $5,131.00$ & 0.42 \\
\hline Total & $1,225,493.00$ & 100.00 \\
\hline
\end{tabular}


Table 5: Calculated data for Benue State based on FAO input-output coefficient in Nigeria (FAO 2016).

\begin{tabular}{lllrrr}
\hline Crops & $\begin{array}{l}\text { Land Area used } \\
\text { (ha) }\end{array}$ & $\begin{array}{l}\text { Yield } \\
(\text { tonnes } / \text { ha })\end{array}$ & $\begin{array}{r}\text { Price } \\
(\$ / \text { tonnes })\end{array}$ & $\begin{array}{r}\text { Planting Cost } \\
(\$ / \text { ha })\end{array}$ & $\begin{array}{r}\text { Net Profit } \\
(\$ / \text { ha })\end{array}$ \\
\hline Cassava & 528,994 & 9.66 & 159.79 & 575.53 & 967.76 \\
Rice & 278,142 & 2.02 & 375.71 & 318.64 & 440.19 \\
Yam & 418,357 & 8.53 & 459.38 & $2,173.81$ & $1,745.19$ \\
\hline
\end{tabular}

Using the data presented in Tables 2, 3, 4, and 5, optimized crop acreage and profit obtained from the suitability model for the three selected crops were compared with production output of the study area. Production output of the study area is presented in Table 6, while the results obtained from the optimized crop pattern are shown in Table 7 .

Table 6: Profit obtained from crop pattern and production for the study area.

\begin{tabular}{llr}
\hline Crops & Land Area (Hectare) & Profit Obtained $(\$)$ \\
\hline Cassava & 528,994 & $512,090,000.00$ \\
Rice & 278,142 & $122,460,000.00$ \\
Yam & 418,357 & $729,910,000.00$ \\
\hline Total & $1,225,493$ & $1,364,460,000.00$ \\
\hline
\end{tabular}

Table 7: Profit optimized from the crop pattern using the model.

\begin{tabular}{llr}
\hline Crops & Land Area (Hectare) & Profit Obtained $(\$)$ \\
\hline Cassava & $535,649.90$ & $518,530,000.00$ \\
Rice & $99,653.06$ & $43,877,000.00$ \\
Yam & $590,190.04$ & $1,029,700,000.00$ \\
\hline Total & $1,225,493$ & $1,592,107,000.00$ \\
\hline
\end{tabular}




\section{Discussion of Results}

Result obtained from the land allocation shown in Table 5 is presented in Table 6 , the total profit is given by $\$ 1,364,460,000.00$. In the study year cassava covered about 43 percent of the land area with a profit of $\$ 512,090,000.00$. Using the optimized model in this study, yam covers 48 percent of the land area with a profit of $\$ 1,029,700,000.00$. A total profit of $\$ 1,592,107,000.00$ was obtained for the three allocated crops. The result obtained from Table 7 show a reallocation of land to crops with an increase in profit value compared to the initial land allocation strategy presented in Table 6. This result shows that a higher profit was obtained using the optimized model to reallocate land to the three selected crops in this study.

\section{Conclusion}

This work considers allocation of agricultural land and crop pattern using land suitability classification. A mathematical model was constructed to maximize crop production putting into consideration market price, cost of planting, yield of crop and soil suitability parameter obtained using geographic map information and remote sensing. A new class of metaheuristic based algorithm was presented and used to solve the constructed model. Result obtained from Table 7 using the constructed model, serves as a sensitizing tool for farm managers on how best to assign crops for cultivation putting into consideration environmental and economic factors. The work highlight the importance of land suitability analysis as well as social and economic factor in the allocation of land to crop for cultivation.

\section{References}

[1] H. Aimin, Uncertainty risk aversion and risk management in agriculture, Agriculture and Agricultural Science Procedia 1 (2010), 152-156. https://doi.org/10.1016/j.aaspro.2010.09.018 
[2] J. H. Holland, Adaptation in Natural and Artificial Systems, University of Michigan Press, Ann Arbor, MI, 1975.

[3] S. Kirkpatrick, J. Gelatt and M. Vecchi, Optimization by simulated annealing, Journal of Science 220(4598) (1983), 671-680.

https://doi.org/10.1126/science.220.4598.671

[4] R. Storn and K. Price, Differential evolution - a simple and efficient heuristic for global optimization over continuous spaces, Journal of Global Optimization 11 (1997), 341-359. https://doi.org/10.1023/A:1008202821328

[5] X. S. Yang, Nature Inspired Metaheuristic Algorithm, Luniver Press, Cambridge, United Kingdom, 2008.

[6] X. S. Yang, Flower pollination algorithm for global optimization, in: Unconventional Computation and Natural Computation, Lecture Notes in Computer Science, vol. 7445, pp. 240-249, Springer, Berlin, Heidelberg, 2012. https://doi.org/10.1007/978-3-642-32894-7_27

[7] Raj Krishna, The optimality of land allocation: a case study of Punjab, Indian Journal of Agricultural Economics 18(1) (1963), 63-73.

[8] J. C. Campbell, J. Radke, J. T. Gless and R. M. Wirtshafter, An application of linear programming and geographic information system: cropland allocation in Antigua, Environment and Planning A 24 (1992), 535-549.

https://doi.org/10.1068/a240535

[9] M. O. Wankhade and H. S. Lunge, Allocation of agricultural land to the major crops of saline track by linear programming approach: a case study, International Journal of Scientific and Technology Research 1(9) (2012), 21-25.

[10] A. M. Alabdulkader, A. I. Al-Amoud and F. S. Awad, Optimization of the cropping pattern in Saudi Arabia using a mathematical programming sector model, Agric. Econ. - Czech 58(2) (2012), 56-60. https://doi.org/10.17221/8/2011-AGRICECON

[11] F. Majeke, J. Majeke, N. Chabuka, J. Mufandaedza, M. Shoko, J. Chirima, T. Makori and C. Matete, A farm resource allocation problem. A case study of model A2 resettled farmers in Bindura, Zimbabwe, International Journal of Economics and Management Science 2(7) (2013), 1-4. 
[12] A. F. Angelo, Hybrid metaheuristics for crop rotation, Anais do Congresso de Matematica (CMAC) (2013), 53-58.

[13] R. Ashutosh and S. Prakash, Optimal allocation of agricultural land for crop planning in Hirakud canal command area using swarm intelligence techniques, ISH Journal of Hydraulic Engineering (2018), 1-13.

https://doi.org/10.1080/09715010.2018.1508375

[14] C. N. Ejieji and A. E. Akinsunmade, Agricultural model for allocation of crops using pollination intelligence method, Applied Computational Intelligence and Soft Computing 2020, Article ID 4830359, 6 pp.

https://doi.org/10.1155/2020/4830359

[15] FAO, A Framework for Land Evaluation, FAO Soils Bulletin No. 32, Rome, Italy, 1976.

[16] C. Sys, E. van Ranst, J. Debaveye and F. Beernaert, Land Evaluation, Part 3: Crop Requirements, General Administration for Development Cooperation, Brussels, Belgium, 1991, 199 pp.

[17] Z. Mosleha, H. Salehia, A. Fasakhodib, A. Jafaric, A. Mehnatkeshd and I. Borujenie, Sustainable allocation of agricultural lands and water resources using suitability analysis and mathematical multi-objective programming, J. GEODERMA 303 (2017), 52-59. https://doi.org/10.1016/j.geoderma.2017.05.015

[18] D. Djaenudin, R. Oktaviain, S. Hartoyo and H. Dwijarabowo, Modelling of land allocation behaviour in Indonesia, Procedia Environmental Sciences 33 (2016), 78-86. https://doi.org/10.1016/j.proenv.2016.03.059

[19] F. Karms, N. Amacha, W. Katerji, W. Wu, A. Domiquez and S. Baydoun, Using remote sensing to improve crop water allocation in scarce water resources environment, International Journal of Science and Research (IJSR) 5(1) (2016), 1481-1495. https://doi.org/10.21275/v5i1.NOV152595

[20] R. C. Abah and B. M. Petja, Crop suitability mapping for rice, cassava, and yam in North Central Nigeria, Journal of Agricultural Science 9(1) (2017), 96-108. https://doi.org/10.5539/jas.v9n1p96

[21] F. Terdoo, T. Gyang and T. R. Iorlamen, Annual cropped area expansion and agricultural production: implications for environmental management in Benue State, 
Nigeria, Ethiopian Journal of Environmental Studies and Management 9(4) (2016), 430-442. https://doi.org/10.4314/ejesm.v9i4.4

[22] FAO, Nigeria at a Glance, 2016.

Retrieved from http://www.fao.org/nigeria/fao-in-nigeria/nigeria-at-aglance/en/

This is an open access article distributed under the terms of the Creative Commons Attribution License (http://creativecommons.org/licenses/by/4.0/), which permits unrestricted, use, distribution and reproduction in any medium, or format for any purpose, even commercially provided the work is properly cited. 